\title{
Toxic effects of multi-walled carbon nanotubes on bivalves: Comparison between functionalized and nonfunctionalized nanoparticles
}

\author{
Lucia De Marchi $^{\mathrm{a}, \mathrm{b}}$, Victor Neto $^{\mathrm{b}}$, Carlo Pretti $^{\mathrm{c}}$, Etelvina Figueira ${ }^{\mathrm{a}}$, Federica Chiellini ${ }^{\mathrm{d}}$, Andrea Morelli ${ }^{\mathrm{d}}$, \\ Amadeu M.V.M. Soares ${ }^{\text {a }}$, Rosa Freitas ${ }^{\text {a,* }}$ \\ a Department of Biology \&' Center for Environmental and Marine Studies (CESAM), University of Aveiro, 3810-193 Aveiro, Portugal \\ ${ }^{\mathrm{b}}$ Department of Mechanical Engineering \& Center for Mechanical Technology and Automation (TEMA), University of Aveiro, 3810-193 Aveiro, Portugal \\ c Department of Veterinary Sciences, University of Pisa, San Piero a Grado, Pisa 56122, Italy \\ d Department of Chemistry and Industrial Chemistry, University of Pisa, Udr INSTM Pisa, Pisa 56126, Italy
}

\section{H I G H L I G H T S}

- Both Nf-MWCNTs and f-MWCNTs altered biochemical responses in Ruditapes philippinarum

- f-MWCNTs generated greater toxicity impacts in exposed clams compared to Nf-MWCNTs

- Inhibition of cholinesterases confirmed neurotoxicity of both MWCNTs materials

- Ruditapes philippinarum is a potential bioindicator to monitor a variety of carbon NMs

\section{A R T I C L E I N F O}

\section{Article history:}

Received 30 August 2017

Received in revised form 4 October 2017

Accepted 4 October 2017

Available online 20 October 2017

Editor: D. Barcelo

Keywords:

Oxidative stress

Toxicity

Ruditapes philippinarum

Unfunctionalized multi-walled carbon

nanotubes

Functionalized multi-walled carbon nanotubes
G R A P H I C A L A B S T R A C T

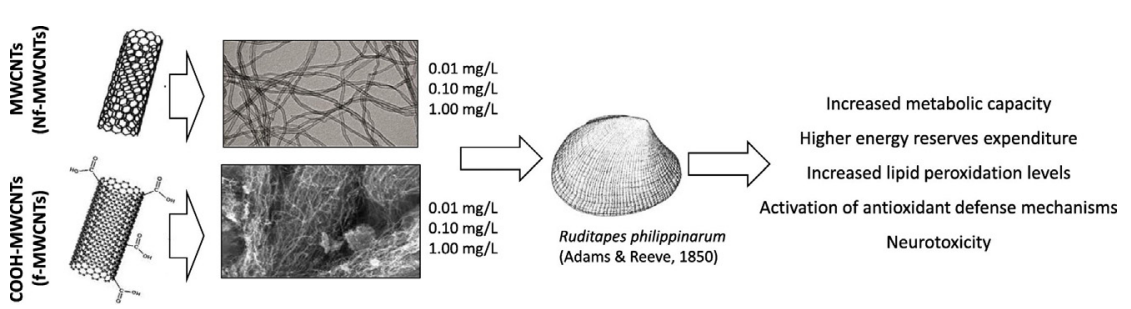

\begin{abstract}
A B S T R A C T
Despite of the large array of available carbon nanotube (CNT) configurations that allow different industrial and scientific applications of these nanoparticles, their impacts on aquatic organisms, especially on invertebrate species, are still limited. To our knowledge, no information is available on how surface chemistry alteration (functionalization) of CNTs may impact the toxicity of these NPs to bivalve species after a chronic exposure. For this reason, the impacts induced by chronic exposure (28 days) to unfunctionalized MWCNTs (Nf-MWCNTs) in comparison with functionalized MWCNTs (f-MWCNTs), were evaluated in R. philippinarum, by measuring alterations induced in clams' oxidative status, neurotoxicity and metabolic capacity. The results obtained revealed that exposure to both MWCNT materials altered energy-related responses, with higher metabolic capacity and lower glycogen, protein and lipid concentrations in clams exposed to these CNTs. Moreover, R. philippinarum exposed to Nf-MWCNTs and f-MWCNTs showed oxidative stress expressed in higher lipid peroxidation and lower ratio between reduced and oxidized glutathione, despite the activation of defense mechanisms (superoxide-dismutase, glutathione peroxidase and glutathione S-transferases) in exposed clams. Additionally, neurotoxicity was observed by inhibition of Cholinesterases activity in organisms exposed to both MWCNTs.
\end{abstract}

(c) 2017 Elsevier B.V. All rights reserved.

\footnotetext{
* Corresponding author at: Departamento de Biologia \& CESAM, Universidade de Aveiro, 3810-193 Aveiro, Portugal.
}

E-mail address: rosafreitas@ua.pt (R. Freitas).

\section{Introduction}

The use of carbon nanomaterials (CNMs) has increased rapidly in the last years, namely due to their important properties such as electromagnetic, optical, catalytic, mechanical, thermal, and pharmokinetics (Petersen and Henry, 2012). 
Currently, carbon nanotubes (CNTs) are one of the most important and commercially used CNMs (Potočnik, 2011; Sanchez et al., 2012). CNTs are hollow graphene cylinders that are microns to millimeters in length and can be divided in single-walled (SWCNTs) with a diameter of 0.7 to $3 \mathrm{~nm}$, and multi-walled (MWCNTs) with a diameter of 10 to $25 \mathrm{~nm}$ (Baughman et al., 2002). CNTs are engineered with a wide variety of core structures and surface functionalizations that change their chemical and physical properties to enhance their suitability for different industrial applications (Arndt et al., 2013). Due to their hydrophobic and non-biodegradable characteristics, which make difficult the dispersion of CNTs in the water (Donaldson et al., 1998), once in the aquatic environment these nanoparticles can be accumulated by aquatic biota through body surface, digestive and respiratory systems (Jackson et al., 2013). Nevertheless, toxicological effects of CNTs, but in general of CNMs, depend on various factors including complex interplay between particle features (e.g., diameter, form, surface charge, and chemistry), concentration, time of exposure, nature of the materials, exposure medium composition, route of particle administration, and target species immune system (Khosravi-katuli et al., 2017). CNTs readily aggregate in solution, and even more in saltwater (Kataoka et al., 2016). For this reason they can get dispersible by functionalization which is achieved through chemical modification such as amidation and esterification of the nanotube-bound carboxylic acids (Sun et al., 2002). The functionalization breaks the nanotube bundles, which is essential to solubility (Sun et al., 2002) and the presence of functional groups on nanotubes surface therefore increases nanotubes dispersibility (Shahnawaz et al., 2017). Specifically, to disperse CNTs in aqueous media, the chemical functionalization of CNTs by introducing polar groups such as carboxyl groups $(-\mathrm{COOH})$ is one of the most common approaches in order to achieve better dispersibility (Shahnawaz et al., 2017). In a study conducted by Shahnawaz et al. (2017), the authors tried to compare the dispersibility and stability in aqueous solution of chemically functionalized (carboxyl groups) MWCNTs (f-MWCNTs) with unfunctionalized MWCNTs revealing that the presence of functional groups on the side wall of MWCNTs significantly increased their dispersibility. Water-dispersible CNTs have shown to have more amorphous carbon fragments as a result of increased oxidation of carbon, and these amorphous fragments can induce higher levels of toxicity to biological systems (Arndt et al., 2013). Recently Kataoka et al. (Kataoka et al., 2016), investigated the toxicity of functionalized (SWCNTs) and unfunctionalized (NSWCNTs) single-walled carbon nanotubes at the concentrations of $10 \mathrm{mg} / \mathrm{L}$ for 14 days on medaka embryos' behavior, and demonstrated that SWCNTs were densely adsorbed over the surface of the egg chorion further inducing acute toxicity to medaka embryos while N-SWCNTs exhibited no toxicity and were not adsorbed onto the egg chorion. Arndt et al. (2013) investigated the toxic effects of acute ( $48 \mathrm{~h}$ ) and chronic exposures (21 days) of Daphnia magna to different types of CNMs that differed in core structure and surface functionalization such as $\mathrm{nC}_{60}$, hydroxylated fullerenes $\left(\mathrm{C}_{60}-\mathrm{OH}_{24}\right)$, SWCNTs, carboxylic acid functionalized SWCNTs (SWCNT-COOH), carboxy-amide functionalized SWCNTs $\left(\mathrm{SWCNT}-\mathrm{CONH}_{2}\right)$, polyethylene glycol functionalized SWCNTs (SWCNT-PEG), and MWCNTs at concentrations of 0,10 , or $50 \mathrm{mg} / \mathrm{L}$. These authors showed that overall nanomaterials up to $10 \mathrm{mg} / \mathrm{L}$ with a CNT core and functionalized were more toxic than $\mathrm{nC}_{60}$ in terms of mortality, reproduction, and growth to daphnids.

Despite the large array of available CNT configurations that allow different applications of these nanoparticles, their impacts on aquatic organisms, especially on invertebrate species, are still limited. Bivalves comprise a wide range of invertebrate organisms with different tolerances to anthropogenic stressors (Coelho et al., 2014; Matozzo et al., 2016a; Torre et al., 2013a; Burgos-Aceves and Faggio, 2017; Torre et al., 2013b; Pagano et al., 2017; Pagano et al., 2016). Specifically, when exposed to pollutants, bivalves present a number of cellular responses that include antioxidant defences (e.g., superoxide dismutase (SOD), glutathione peroxidase (GPx), catalase (CAT)), metabolization mechanisms (e.g., glutathione S-transferases (GSTs)), cellular damage (e.g., lipid peroxidation (LPO)) and neurotoxicity (e.g., acetylcholinesterase (AChE)) (Bebianno et al., 2004). While several studies showed that these biochemical markers are useful in detecting possible damages under metal pollution (Velez et al., 2016; Wang et al., 2011; Yesudhason et al., 2013; Gomes et al., 2013) eutrophication (Verdelhos et al., 2005) and pharmaceuticals (Freitas et al., 2015; Antunes et al., 2013; Matozzo et al., 2016b; Correia et al., 2016), less is known on the biochemical alterations induced by CNMs in this group of organisms (Cattaneo et al., 2009; De Marchi et al., 2017a; Canesi and Corsi, 2015; Miller et al., 2015; Matranga and Corsi, 2012; De Marchi et al., 2017b).

The Manila clam Ruditapes philippinarum (Adams \& Reeve, 1850), because of its considerable commercial value, was intentionally introduced and became established in several regions worldwide including the Pacific coast of North America and along the shores of Europe from the United Kingdom to the Mediterranean basin (Moura et al., 2017). This species has been already used to assess a diversity of stressors due to its wide distribution, long life cycle, ease of collection, and high capacity to bioaccumulate contaminants (Bebianno et al., 2004; Zhang et al., 2011; Savorelli et al., 2017). Nevertheless, to our knowledge, no information is available on how surface chemistry alteration (functionalization) of CNTs may impact the toxicity of these pollutants to this species after a chronic exposure. For this reason, the impacts induced by unfunctionalized MWCNTs (Nf-MWCNTs) and functionalized MWCNTs (f-MWCNTs) were evaluated in R. philippinarum, by measuring alterations induced in clams' oxidative status, neurotoxicity and metabolic capacity at the end of 28 days.

\section{Materials and methods}

\subsection{Experimental setup}

R. philippinarum specimens were collected in the northwest Atlantic coast of Portugal $\left(40^{\circ} 38^{\prime} \mathrm{N}, 8^{\circ} 45^{\prime} \mathrm{W}\right)$. Bivalves with similar size (mean length: $23.2 \pm 0.32 \mathrm{~mm}$; mean weight: $7.9 \pm 1.7$ ) were used to prevent differences on organisms' CNTs accumulation and biochemical responses.

For 7 days, the collected clams were placed in different aquaria $(20 \mathrm{~L}$ each) for depuration and acclimation to laboratory conditions. Artificial sea salt (Tropic Marin ${ }^{\circledR}$ Sea Salt) (salinity 28) was added to deionized water to fill the aquaria. During the acclimation period organisms were under $12 \mathrm{~h}$ light: $12 \mathrm{~h}$ dark photoperiod, temperature $\left(18 \pm 1{ }^{\circ} \mathrm{C}\right)$ and aerated conditions. Every two-three days' specimens were fed with AlgaMac Protein Plus, Aquafauna Bio-Marine, Inc. (150,000 cells/animal).

After the acclimation and depuration period, 15 organisms per condition ( 3 aquaria/replicates per condition, with 5 organisms per aquarium/replica) were exposed during 28 days to two types of MWCNTs: unfunctionalized MWCNTs (Nf-MWCNTs) and chemically functionalized MWCNTs by introducing polar groups such as carboxyl groups $(-\mathrm{COOH})$ (f-MWCNTs), both at the concentrations of $0.01 ; 0.10$ and $1.00 \mathrm{mg} / \mathrm{L}$. The choice of these two CNTs was based on their different physical and chemical properties, different behavior on the water media (aggregation/disaggregation, adsorption/desorption, sedimentation/resuspension and dissolution) (Arndt et al., 2013) as well as their industrial applicability. The exposure concentrations of both MWCNT were selected taking into consideration previous studies conducted by De Marchi et al. (De Marchi et al., 2017b; De Marchi et al., 2017c) which, using the same species (De Marchi et al., 2017b) or other invertebrates (polychaetes) (De Marchi et al., 2017c) and the same range of unfunctionalized MWCNTs, revealed observable biochemical responses from both these organisms, although the dynamic probabilistic material flow model (DP-MFA) showed that predicted environmental concentrations of CNTs in the water in the range of ng/L (Sun et al., 2016).

Salinity, $\mathrm{pH}$, temperature and aeration conditions in each aquarium were set up as in the acclimation period (see above). Both Nf-MWCNT and f-MWCNT concentrations were re-established weekly after complete water renewals to ensure the same exposure concentrations 
during the experiment. To promote stable suspension of both CNTs in the water column (Hwang et al., 2007), the Nf-MWCNTs was sonicated for $1 \mathrm{~h}$ using $30 \mathrm{~Hz}$ ultrasound bath (IKA Labortechnik IKASONIC U50), while the f-MWCNTs, (Shahnawaz et al., 2017), was sonicated by probe sonicator $\left(55 \mathrm{~W} \mathrm{~cm}^{-2}\right.$ ) (UP 400S, hielscher Ultrasound Technology) for few minutes. The added MWCNTs (f and Nf) were homogenously dispersed in the seawater using one submersible circulation pump per aquarium, which diminishes the possibility that the dynamical equilibrium between gravitational settling and Brownian motion can result in the presence of CNTs near the bottom-water interface (Vonk et al., 2010).

\subsection{MWCNTs characterization (Nf-MWCNTs and f-MWCNTs)}

Both unfunctionalized and functionalized MWCNT materials were produced via the Catalytic Chemical Vapor Deposition (CCVD) process and characterized using Scanning Electron Microscopy (SEM) and Transmission electromicrographs (TEM) (Fig. 1A and B respectively). The NfMWCNTs were purchased from Nanocyl S.A. (MWCNTs: NC7000 series, http://www.nanocyl.com) while f-MWCNTs from Times Nano: Chengdu Organic Chemicals Co. Ltd., Chinese Academy of Sciences (MWCNTsCOOH: TNMC1 series, http://www.timesnano.com) and manufacturer's specifications are showed in Table 1.

The concentrations of both MWCNTs used in this study $(0.01,0.10$ and $1.00 \mathrm{mg} / \mathrm{L}$ ) were prepared from a stock solution of $50 \mathrm{mg} / \mathrm{L}$ concentration each. For particles characterization in the exposure medium,
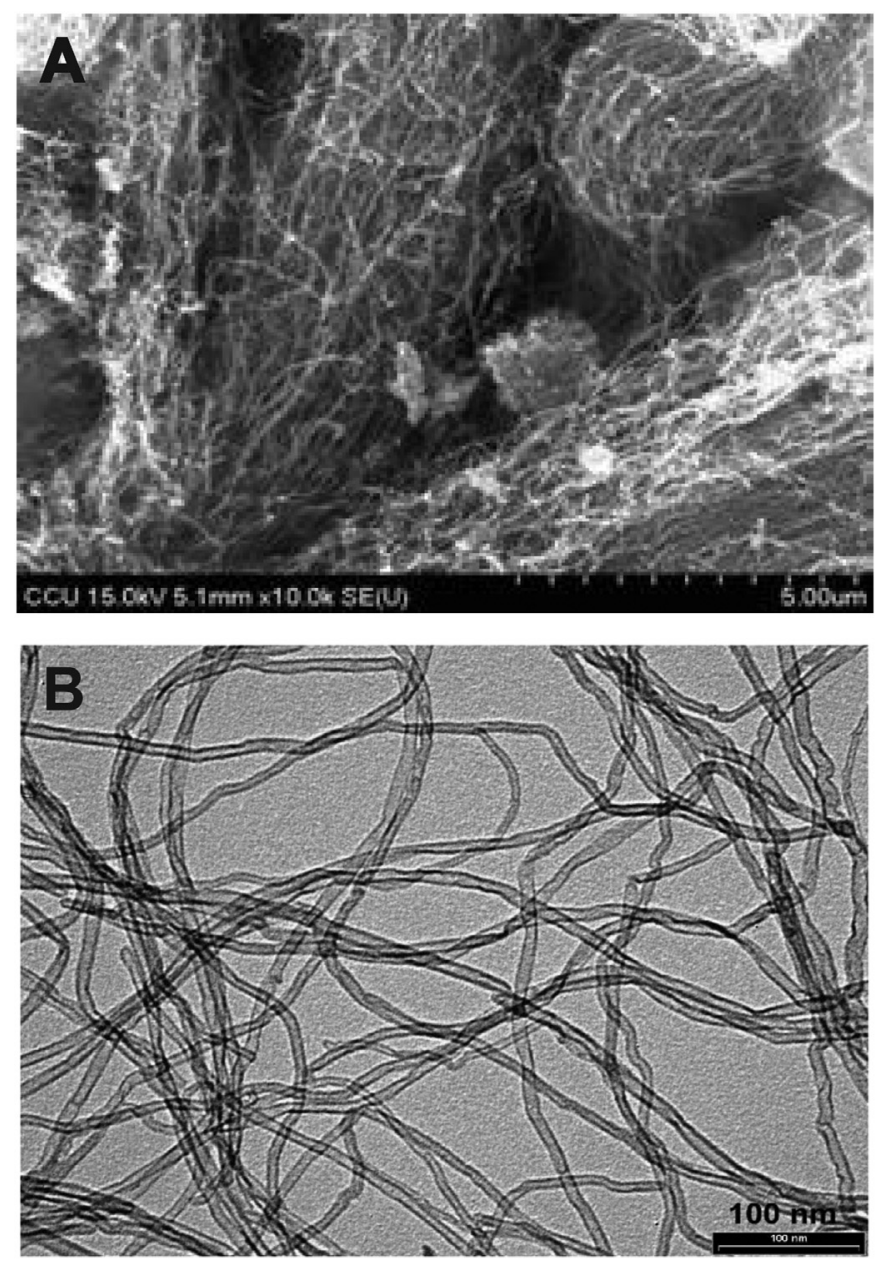

Fig. 1. A: Scanning Electron Microscopy (SEM) of the functionalized form MWCNTs-COOH (f-MWCNTs) produced via the catalytic carbon vapor deposition (CCVD) process; B: Transmission Electron Microscopy (TEM) of the powder form of MWCNTs produced via the catalytic carbon vapor deposition (CCVD) process. before water renewals, water samples ( $10 \mathrm{~mL}$ each) were collected from each aquarium at different periods: t0: time zero, immediately after medium contamination (dispersed Nf-MWCNT and f-MWCNT concentrations in artificial seawater); t7: 1 week after exposure, immediately before water renewals; t28: water samples collected after the fourth week of exposure.

Dynamic light scattering (DLS) measurements were carried out with a Delsa Nano C Beckman Coulter, Inc. (Fullerton, CA) equipped with a laser diode operating at $658 \mathrm{~nm}$. Scattered light was detected at $165^{\circ}$ angle and analyzed with a log correlator over 120 accumulations for a $2.0 \mathrm{~mL}$ of sample in a glass size cell. Each sample was reproducibly shaken before analysis and exposed to an appropriate number of DLS measurements needed to obtain at least three valid data. When no colloidal material was detected, result was reported as Invalid data (I.d.). The calculation of the particle size distribution and distribution averages were performed by CONTIN particle size distribution analysis routines through Delsa Nano 3.73 software. The hydrodynamic radius and polydispersity index of the analyzed dispersions were calculated on three replicates of each sample by the cumulant method. Due to the inherent heterogeneity and colloidal instability of the analyzed samples, DLS analyses were repeated five times to ensure reproducible results. The results are reported in the Table 2.

\subsection{Biochemical parameters}

After 28 days exposure, clams used for biomarker analysis ( 3 per aquarium, 9 per condition) were frozen, pulverized individually with liquid nitrogen and divided in $0.5 \mathrm{~g}$ aliquots. Extractions were performed with specific buffers (De Marchi et al., 2017d; De Marchi et al., 2017c) for each biomarker. Biochemical analyses were performed in duplicate for each sample and biomarker with a BioTek Synergy HT micro-plate Reader. For lipids content determination the remaining organisms (2 per aquarium, 6 per condition) were dried at $60^{\circ} \mathrm{C}$ for $48 \mathrm{~h}$.

\subsubsection{Energy reserves and metabolic activity}

Protein (PROT) content was determined following the spectrophotometric method of Biuret (Robinson and Hogden, 1940), and bovine serum albumin (BSA) was used as standard $(0-40 \mathrm{mg} / \mathrm{mL})$. Absorbance was measured at $540 \mathrm{~nm}$. Concentrations of PROT were expressed in $\mathrm{mg}$ per $\mathrm{g}$ fresh weight (FW).

Glycogen (GLY) content was quantified following the sulphuric acid method (Dubois et al., 1956), (glucose standards (0-2 mg/mL)). Absorbance was read at $540 \mathrm{~nm}$ and GLY expressed in $\mathrm{mg}$ per $\mathrm{g}$ of FW.

Lipid (LIP) content was determined following Yi et al. (2011). The absorbance was measured at $540 \mathrm{~nm}$ and the results were expressed in percentage per g dry weight (DW).

The electron transport system (ETS) activity was measured following King and Packard (1975) revised by De Coen and Janssen (1997) methods. The absorbance was measured at $490 \mathrm{~nm}$ during $10 \mathrm{~min}$ with intervals of $25 \mathrm{~s}$. The results were expressed in $\mathrm{nmol} / \mathrm{min}$ per $\mathrm{g}$ of $\mathrm{FW}$.

\subsubsection{Antioxidant defences and biotransformation mechanisms}

To quantify Superoxide-dismutase (SOD) activity, the method of Beauchamp and Fridovich (1971) was performed with a standard curve including SOD standards between 0.25 and $60 \mathrm{U} / \mathrm{mL}$. Results were expressed in $\mathrm{U}$ per $\mathrm{g}$ of $\mathrm{FW}(\mathrm{U}=1.0 \mu \mathrm{mol}$ nitroblue tetrazolium (NBT) per min). The absorbance was measured at $560 \mathrm{~nm}$.

Glutathione peroxidase (GPx) was quantified in accordance with Paglia and Valentine (1967) methods. The results were expressed in U per $\mathrm{g}$ of $\mathrm{FW}(\mathrm{U}=1.0 \mu \mathrm{mol}$ NADPH oxidized per $\mathrm{min})$. The absorbance was read at $340 \mathrm{~nm}$ in $10 \mathrm{~s}$ intervals during $5 \mathrm{~min}$.

Glutathione-S-transferase (GSTs) activity was determined using the extinction coefficient $9.6 \mathrm{mM} \mathrm{cm}^{-1}$ for CDNB and the absorbance was read at $340 \mathrm{~nm}$ (Habig et al., 1976). Results were expressed in U per $\mathrm{g}$ of FW where $U$ is defined as the amount of enzyme that produces 1 $\mu \mathrm{mol}$ of dinitrophenyl thioether per min. 
Table 1

Characterization of the powder form of MWCNTs (Nf-MWCNTs) and MWCNTs-COOH (f-MWCNTs).

\begin{tabular}{|c|c|c|c|c|c|c|}
\hline & Diameter (nm) & Length $(\mu \mathrm{m})$ & Carbon purity (\%) & Surface area $\left(\mathrm{m}^{2} / \mathrm{g}\right)$ & Amorphous carbon (mol\%) & $-\mathrm{COOH}(\mathrm{wt} \%)$ \\
\hline Nf-MWCNTs & 9.5 & 1.5 & 90 & $250-300$ & $*$ & - \\
\hline f-MWCNTs & $2-5$ & $10-30$ & 98 & 400 & $8-10$ & 3.86 \\
\hline
\end{tabular}

* Pyrolytically deposited carbon on the surface of MWCNTs.

\subsubsection{Indicators of cellular damage}

Lipid peroxidation (LPO), was determined according to the method described by Ohkawa et al. (1979), by the quantification of malondialdehyde (MDA) and expressed in nmol of MDA formed per $\mathrm{g}$ of FW. Absorbance was measured at $535 \mathrm{~nm}$.

Reduced (GSH) and oxidized (GSSG) glutathione contents were measured at $412 \mathrm{~nm}$ (Rahman et al., 2014) and used as standards (0-60 $\mu \mathrm{mol} / \mathrm{L})$. GSH and GSSG concentrations were expressed in nmol per $\mathrm{g}$ FW. The calculation of the ratio between oxidized and reduced glutathione was done dividing the GSH values by $2 \times$ the amount of GSSG.

\subsubsection{Neurotoxicity}

Acetylthiocholine iodide (ATChI, $470 \mu \mathrm{M}$ ) substrates were used for the determination of Acetylcholinesterase (ATChI-ChE) following the methods of Ellman et al. (1961) and modification by Mennillo et al. (2017). Enzyme activities were recorded continuously for $5 \mathrm{~min}$ at $412 \mathrm{~nm}$ and expressed in nmol per min per $\mathrm{g}$ FW.

\subsection{Data analysis}

All the biochemical results (PROT, GLY LIP, ETS, SOD, GPx, GSTs, LPO, GSH/GSSG, and ATChI-ChE) were submitted to hypothesis testing using permutational multivariate analysis of variance with the PERMANOVA + add-on using PRIMER v6 software. The pseudo-F $p$-values in the PERMANOVA main tests were evaluated in terms of significance. When significant differences were observed in the main test, pairwise comparisons were performed. Values lower than $0.05(p \leq 0.05)$ were considered as significantly different. The null hypotheses tested were: i) for each biomarker and for each MWCNT material, no significant differences existed among exposure concentrations $(0.00,0.01,0.10,1.00 \mathrm{mg} / \mathrm{L})$; ii) for each biomarker and for each exposure concentration $(0.00,0.01,0.10$, $1.00 \mathrm{mg} / \mathrm{L}$ ) no significant differences existed between MWCNT materials. Significant differences concerning each biomarker among exposure

Table 2

Dynamic Light Scattering (DLS) data of Size (nm) and Polydispersity Index (PDI) in exposure medium $(0.01 \mathrm{mg} / \mathrm{L}$ f-MWCNTs; $0.01 \mathrm{mg} / \mathrm{L}$ Nf-MWCNTs; $0.10 \mathrm{mg} / \mathrm{L} \mathrm{f-MWCNTs}$ $0.10 \mathrm{mg} / \mathrm{L}$ Nf-MWCNTs; $1.00 \mathrm{mg} / \mathrm{L} \mathrm{f-MWCNTs}$ and $1.00 \mathrm{mg} / \mathrm{L}$ Nf-MWCNTs) collected at different exposure periods (t0; $\mathrm{t} 7$ and t28). I.d.: "Invalid data" (no colloidal material detected into the analyzed sample). n.d.: absence of triplicates values for mean size calculation.

\begin{tabular}{llll}
\hline Samples & Nanoparticles & Size $(\mathrm{nm})$ & PDI \\
\hline t0_0.01 mg/L & Nf-MWCNTs & 3434.0 & n.d \\
& f-MWCNTs & 2987.3 & - \\
t7_0.01 mg/L & Nf-MWCNTs & 3432.2 & n.d \\
& f-MWCNTs & n.d. $(5$ I.d. $)$ & - \\
t28_0.01 mg/L & Nf-MWCNTs & 3430.0 & n.d \\
& f-MWCNTs & n.d. (5 I.d.) & - \\
t0_0.10 mg/L & Nf-MWCNTs & 2407.1 & 0.98 \\
& f-MWCNTs & 3244.8 & 1.30 \\
t7_0.10 mg/L & Nf-MWCNTs & n.d (3 I.d.) & n.d. \\
& f-MWCNTs & n.d. (5 I.d.) & - \\
t28_0.10 mg/L & Nf-MWCNTs & 4542.7 & 1.81 \\
& f-MWCNTs & n.d. (5 I.d.) & - \\
t0_1.00 mg/L & Nf-MWCNTs & 5714.4 & 1.45 \\
& f-MWCNTs & 3806.1 & 1.30 \\
t7_1.00 mg/L & Nf-MWCNTs & $3602.9(1$ I.d.) & 1.39 \\
& f-MWCNTs & n.d. (5 I.d.) & - \\
t28_1.00 mg/L & Nf-MWCNTs & 3865.2 & 1.40 \\
& f-MWCNTs & n.d. (5 I.d.) & - \\
\hline
\end{tabular}

concentrations were represented with different letters (lowercase letters for f-MWCNTs; uppercase letters for Nf-MWCNTs). Significant differences concerning each biomarker between the two MWCNT materials at each exposure concentration were represented with asterisks.

The matrix gathering biochemical descriptors per condition were used to calculate an Euclidean distance similarity matrix. The similarity matrix was simplified through the calculation of the distance among centroids matrix, which was then submitted to ordination analysis, performed by Principal Coordinates (PCO). Pearson correlation vectors of biochemical descriptors (correlation $>0.75$ ) were provided.

\section{Results}

\subsection{MWCNTs characterization (Nf-MWCNTs and f-MWCNTs)}

As reported in the literature, DLS measurements have been routinely carried out as an effective tool to observe the evolution of relative particle size distributions of carbon nanotubes in aqueous media as a function of time (Moon et al., 2009; Wang et al., 2010; Xu et al., 2011). In the present work, DLS measurements were carried out to obtain data regarding the tendency to aggregate and the settling behavior of suspended CNTs in aqueous media. In Table 2 results of the Dynamic Light Scattering (DLS) characterization, used to detect the presence of macro/micro/ nano-sized Nf-MWCNTs and f-MWCNTs particle aggregates in aqueous media under the adopted experimental conditions are reported. The mean size of the suspended particle aggregates was determined by application of the cumulant method. The mean diameters of f-MWCNTs particles at the time zero (t0) were found to be smaller than those calculated for Nf-MWCNTs aggregates under the same experimental conditions indicating an improved dispersion in the aqueous media (Table 2).

DLS and polydispersity index (PDI) analysis of experimental samples exposed to different concentrations of f-MWCNTs $(0.01 \mathrm{mg} / \mathrm{L}, 0.10 \mathrm{mg} / \mathrm{L}$, $1.00 \mathrm{mg} / \mathrm{L}$ ) among collection periods ( $\mathrm{t} 7$ and $\mathrm{t} 28$ ) did not detect measurable macro/micro/nano-sized particle aggregates (Table 2). Concerning samples prepared with $0.01 ; 0.10$ and $1.00 \mathrm{mg} / \mathrm{L}$ of Nf-MWCNTs observed among collection periods ( $0, \mathrm{t} 7$ and $\mathrm{t} 28$ ), these were unstable and characterized by the presence of micro-sized aggregates whose hydrodynamic radius was directly correlated with the nominal concentrations of the samples (Table 2). Furthermore, a time-dependent increase of the PDI in each condition was also possible to observe, due to the generation of large particles or aggregates in the investigated samples, with one exception for $0.01 \mathrm{mg} / \mathrm{L}$ Nf-MWCNTs, where the detection of measurable macro/micro/nano-sized particle aggregates was not possible.

\subsection{Biochemical parameters}

\subsubsection{Energy reserve and metabolic activity}

$R$. philippinarum exposed to Nf-MWCNTs presented a decrease in PROT content with the increase of exposure concentration, with significant differences among all exposure conditions (Fig. 2A). Clams exposed to f-MWCNTs presented significantly lower PROT content compared to non-exposed organisms, but in this case no significant differences were observed among clams exposed to different MWCNTs concentrations (Fig. 2A). Significant differences between the two MWCNT materials at each of the tested concentrations (control-0.00, 0.01, 0.10, $1.00 \mathrm{mg} / \mathrm{L}$ ) were only detected in clams exposed to $0.01 \mathrm{mg} / \mathrm{L}$, with higher PROT content in organisms exposed to Nf-MWCNTs. 


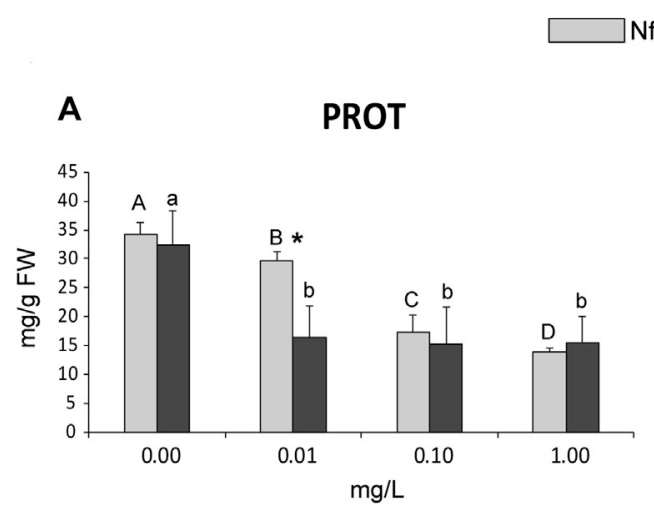

$N f \square f$
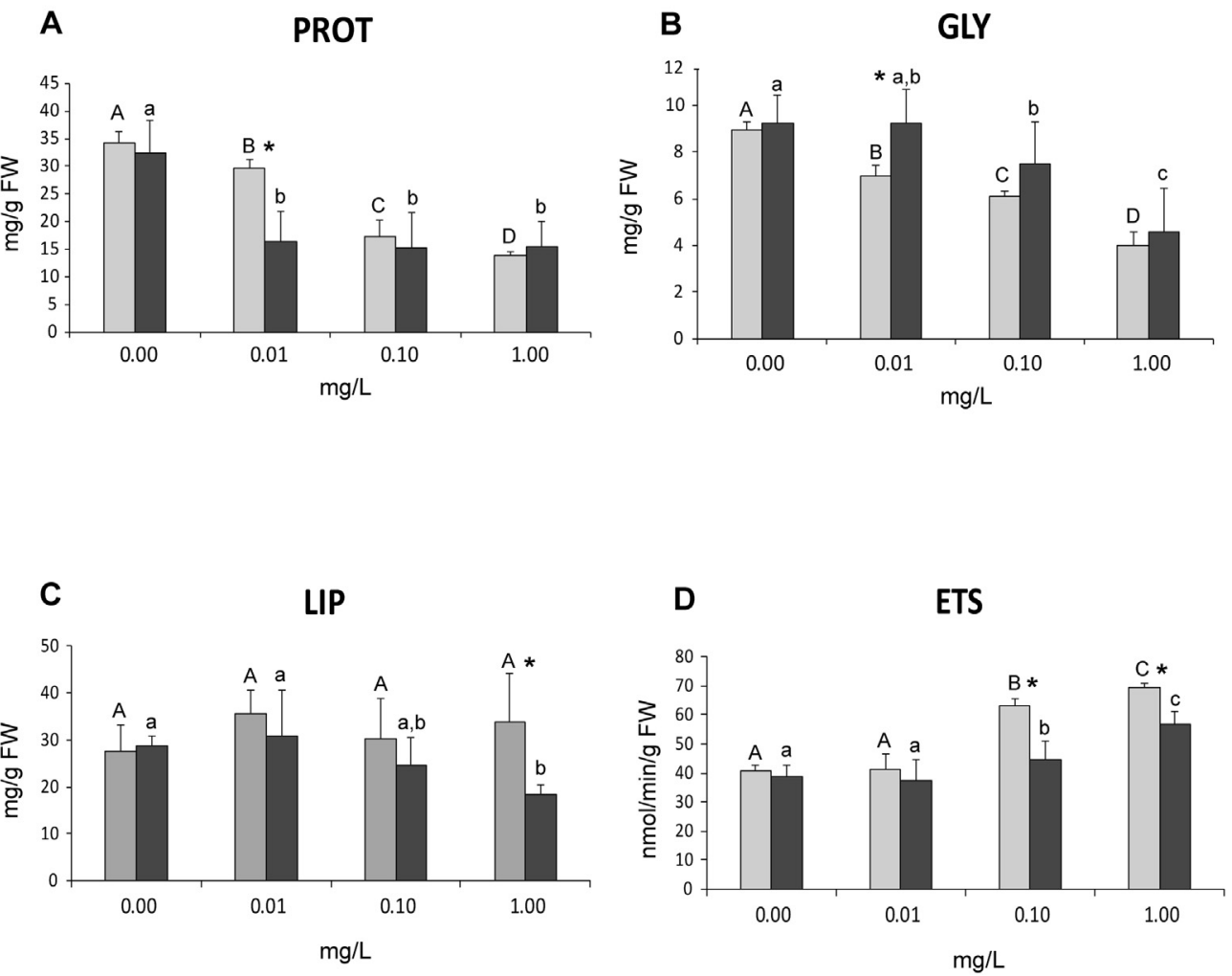

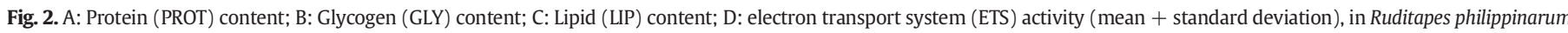

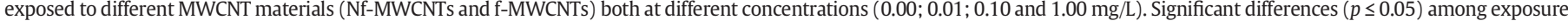

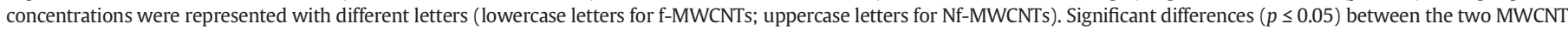
materials at each exposure concentration were represented with asterisks.

All the clams exposed to Nf-MWCNTs presented decreased GLY content along the increase of exposure gradient, with significant differences among all tested conditions (Fig. 2B). A similar pattern was observed in organisms under f-MWCNTs, with significantly lower GLY content in clams exposed to 0.10 and $1.00 \mathrm{mg} / \mathrm{L}$ f-MWCNTs compared to control organisms (Fig. 2B). When comparing organisms exposed to two different MWCNT materials, significant differences in GLY content were observed in organisms exposed to $0.01 \mathrm{mg} / \mathrm{L}$ conditions (Fig. 2B).

The LIP content in organisms exposed to Nf-MWCNTs was similar among all exposure concentrations, with no significant differences among conditions, while the LIP content decreased at 0.10 and $1.00 \mathrm{mg} / \mathrm{L}$ in clams under f-MWCNTs, with significantly lower LIP content at the highest concentration (Fig. 2C). Significant differences in LIP content between the two MWCNT materials was observed at $1.00 \mathrm{mg} / \mathrm{L}$ (Fig. 2C).

In R. philippinarum exposed to Nf-MWCNTs and f-MWCNTs, the ETS activity significantly increased with the increase of exposure concentrations, with significantly higher ETS activity in organisms exposed to 0.10 and $1.00 \mathrm{mg} / \mathrm{L}$ in comparison to organisms exposed to control and $0.01 \mathrm{mg} / \mathrm{L}$ (Fig. 2D). Between MWCNTs materials, significant differences in ETS activity were recorded at the two highest concentrations $(0.10$ and $1.00 \mathrm{mg} / \mathrm{L}$ ) with higher activity in organisms exposed to NfMWCNTs (Fig. 2D).

\subsubsection{Antioxidant defences and biotransformation mechanisms}

The activity of SOD in clams exposed to Nf-MWCNTs increased with the increase of exposure concentrations with significant differences among conditions, while in organisms exposed to f-MWCNTs SOD activity was only significantly increased at 0.10 and $1.00 \mathrm{mg} / \mathrm{L}$ in comparison to organisms exposed to the remaining conditions (control- $0.00 \mathrm{mg} / \mathrm{L}$ and $0.01 \mathrm{mg} / \mathrm{L}$ ) (Fig. 3A). Significant differences between $R$. philippinarum submitted to different MWCNT materials for each of the tested concentrations were observed at 0.10 and $1.00 \mathrm{mg} / \mathrm{L}$ with higher SOD activity in organisms exposed to f-MWCNTs (Fig. 3A).

The activity of GPx in clams exposed to Nf-MWCNTs significantly increased at 0.01 and $0.10 \mathrm{mg} / \mathrm{L}$ in comparison to control values, while at the highest exposure concentration $(1.00 \mathrm{mg} / \mathrm{L})$ the activity of GPx was significantly lower than control levels (Fig. 3B). Different GPx activity was recorded in clams under f-MWCNTs, where significantly higher activity was observed between the two highest f-MWCNTs ( 0.10 and $1.00 \mathrm{mg} / \mathrm{L}$ ) and the remaining conditions (control and $0.01 \mathrm{mg} / \mathrm{L}$ ) (Fig. 3B). Between MWCNT materials, significant differences in GPx activity were observed at all exposure conditions, with higher values in clams exposed to Nf-MWCNTs at concentrations 0.01 and $0.10 \mathrm{mg} / \mathrm{L}$ while at the highest exposure concentration ( $1.00 \mathrm{mg} / \mathrm{L})$ significantly higher GPx activity was observed in clams exposed to f-MWCNTs (Fig. 3B).

Clams exposed to Nf-MWCNTs decreased the GSTs activity with the increase of exposure concentrations with significant differences between control and the remaining conditions as well as between clams exposed to 0.10 and 1.00 and those exposed to $0.01 \mathrm{mg} / \mathrm{L}$ (Fig. 3C). The activity of GSTs also decreased with the increase of exposure concentrations in organisms under f-MWCNTs, with significant differences between control and individuals exposed to 0.10 and $1.00 \mathrm{mg} / \mathrm{L} \mathrm{f}$ MWCNTs (Fig. 3C). Comparing GSTs activity in R. philippinarum exposed to different MWCNT materials, significant differences were only recorded at the two highest concentrations ( 0.10 and $1.00 \mathrm{mg} / \mathrm{L}$ ), with organisms under Nf-MWCNTs presenting higher enzymatic activities (Fig. 3C). 
$\mathrm{Nf} \square \mathrm{q}$

A

SOD

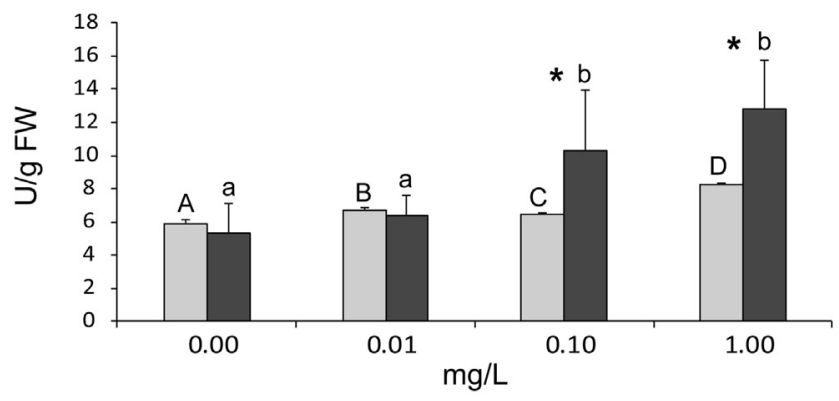

B

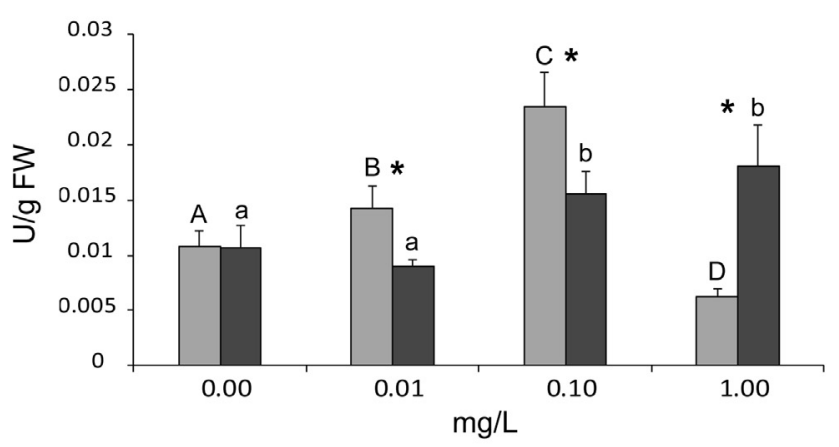

C

GSTs

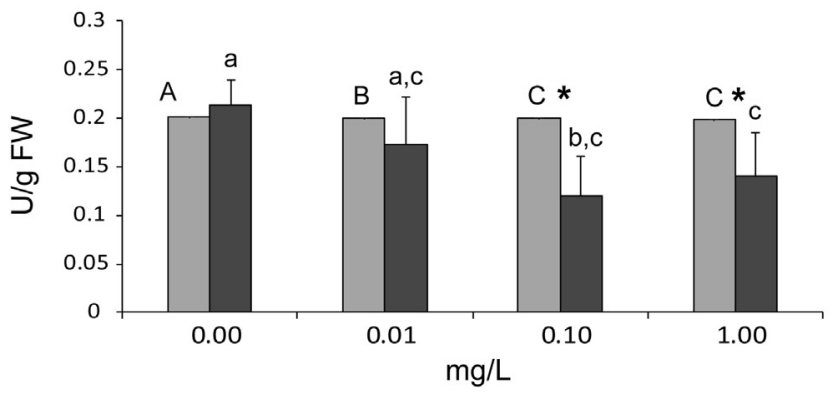

Fig. 3. A: Superoxide dismutase (SOD) activity; B: Glutathione peroxidase (GPx) activity; C: Glutathione S-transferases (GSTs) activity (mean + standard deviation), in Ruditapes philippinarum exposed to different MWCNT materials (Nf-MWCNTs and f-MWCNTs) both at different concentrations $(0.00 ; 0.01 ; 0.10$ and $1.00 \mathrm{mg} / \mathrm{L}$ ). Significant differences ( $p \leq$ 0.05 ) among exposure concentrations were represented with different letters (lowercase letters for f-MWCNTs; uppercase letters for Nf-MWCNTs). Significant differences ( $p \leq 0.05)$ between the two MWCNT materials at each exposure concentration were represented with asterisks.

\subsubsection{Indicators of cellular damage}

Specimens exposed to Nf-MWCNTs increased LPO levels with the increase of exposure concentrations, with significant differences among all tested conditions (Fig. 4A). Increased LPO was also observed in clams under f-MWCNTs, with significant differences among contaminated and non-contaminated (control) organisms and no significant differences in LPO levels among organisms exposed to different NFMWCNT concentrations (Fig. 4A). Between MWCNT materials, significant differences were observed at all exposure concentrations $(0.01$, $0.10,1.00 \mathrm{mg} / \mathrm{L}$ ), with the highest LPO levels in R. philippinarum under f-MWCNTs (Fig. 4A).

At both tested CNTs, (Nf-MWCNTs and f-MWCNTs), GSH/GSSG was significantly lower in clams exposed to 0.10 and $1.00 \mathrm{mg} / \mathrm{L}$ in comparison to clams exposed to 0.00 (control) and $0.01 \mathrm{mg} / \mathrm{L}$ (Fig. 4B). Clams
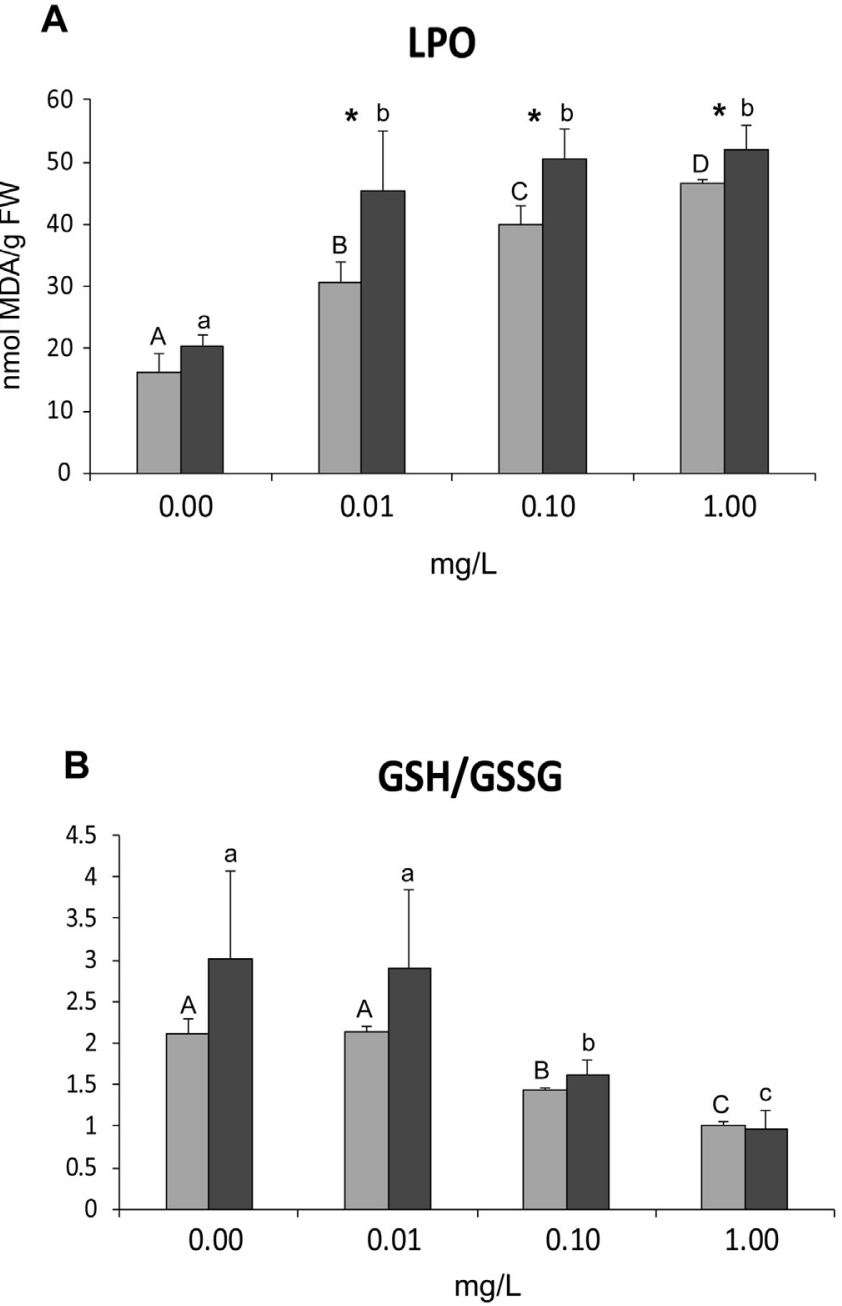

Fig. 4. A: Lipid peroxidation (LPO) levels; B: GSH/GSSG (mean + standard deviation), in Ruditapes philippinarum exposed to different MWCNT materials (Nf-MWCNTs and fMWCNTs) both at different concentrations $(0.00 ; 0.01 ; 0.10$ and $1.00 \mathrm{mg} / \mathrm{L})$. Significant differences $(p \leq 0.05)$ among exposure concentrations were represented with different letters (lowercase letters for f-MWCNTs; uppercase letters for Nf-MWCNTs). Significant differences $(p \leq 0.05)$ between the two MWCNT materials at each exposure concentration were represented with asterisks.

exposed to control and $0.01 \mathrm{mg} / \mathrm{L}$ showed no significant differences in $\mathrm{GSH} / \mathrm{GSSG}$ values. Comparing GSH/GSSG values in organisms exposed to different MWCNTs at each of the tested concentrations, no significant differences were noticed between organisms exposed to different MWCNTs, although higher values were observed for f-MWCNTs organisms (Fig. 4B).

\subsubsection{Neurotoxicity}

ATChI-ChE activity presented significantly lower values in contaminated organisms exposed to Nf-MWCNTs in comparison to organisms under control, but no significant differences were observed between organisms exposed to 0.01 and $0.10 \mathrm{mg} / \mathrm{L}$ as well as between organisms exposed to 0.10 and $1.0 \mathrm{mg} / \mathrm{L}$ (Fig. 5). Decreased of ATChI-ChE activity was also observed in organisms exposed to f-MWCNTs, with significant differences between individuals at control and all the remaining conditions with the lowest value at the highest exposure concentration. However, no significant differences were observed between clams under 0.01 and $0.10 \mathrm{mg} / \mathrm{L}$ (Fig. 5). Comparing MWCNT materials, significant differences in terms of ATChI-ChE activity were obtained at the lowest 
$\square \mathrm{Nf} \square \mathrm{f}$

\section{ATChI-ChE}

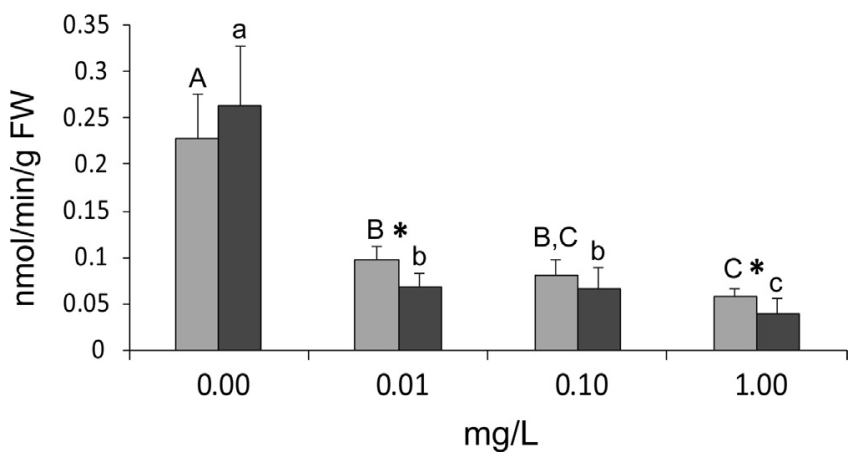

Fig. 5. ATChI-ChE activity in Ruditapes philippinarum exposed to different MWCNT materials (Nf-MWCNTs and f-MWCNTs) both at different concentrations $(0.00 ; 0.01 ; 0.10$ and $1.00 \mathrm{mg} / \mathrm{L}$ ). Significant differences $(p \leq 0.05)$ among exposure concentrations were represented with different letters (lowercase letters for f-MWCNTs; uppercase letters for Nf-MWCNTs). Significant differences $(p \leq 0.05)$ between the two MWCNT materials at each exposure concentration were represented with asterisks.

$(0.01 \mathrm{mg} / \mathrm{L})$ and the highest $(1.00 \mathrm{mg} / \mathrm{L})$ concentrations, with higher values in organisms exposed to Nf-MWCNTs (Fig. 5).

\subsection{Multivariate analysis}

Principal coordinates analysis (PCO) graph obtained is shown in Fig. 6. PCO axis 1 explained $56.9 \%$ total variation, while $\mathrm{PCO}$ axis 2 explained $18.8 \%$ (Fig. 6). PCO1 separated individuals exposed to both control conditions ( $\mathrm{Nf}$ and f-MWCNTs) and $0.01 \mathrm{mg} / \mathrm{L}$ Nf-MWCNTs at the negative side from clams exposed to 0.10 and $1.00 \mathrm{mg} / \mathrm{L}$ of both MWCNT materials and $0.01 \mathrm{mg} / \mathrm{L}$ f-MWCNT in the positive side. PCO2 separated individuals exposed to $0.10 \mathrm{mg} / \mathrm{L}$ and $1.00 \mathrm{mg} / \mathrm{L} \mathrm{Nf-MWCNTs}$ in the negative side from the remaining conditions in the positive side. Non-

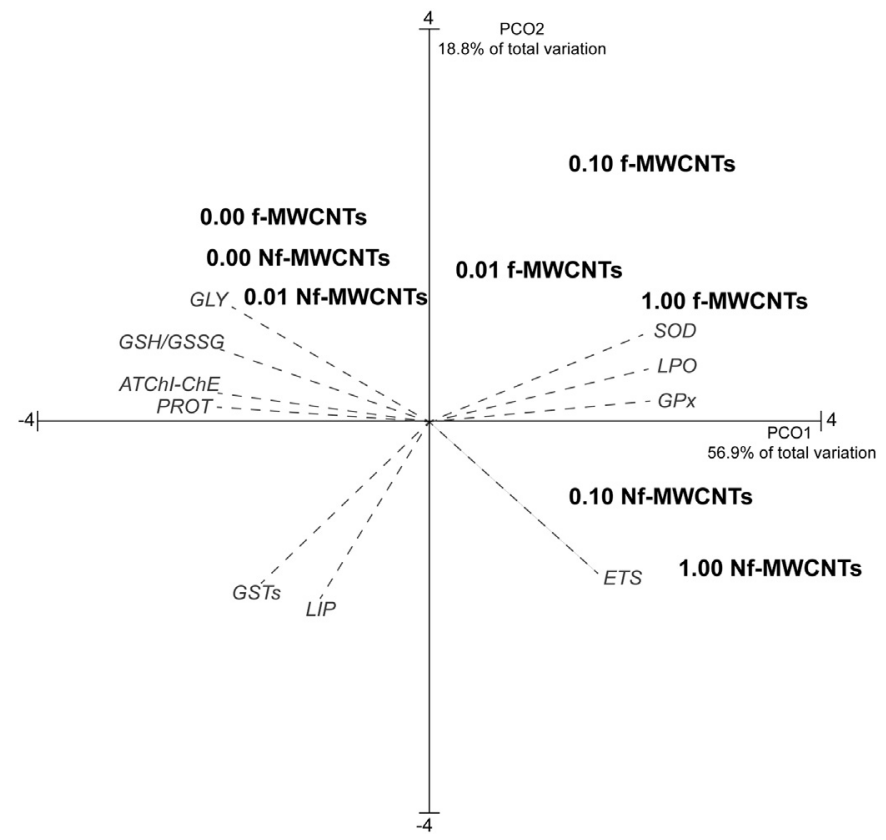

Fig. 6. Centroids ordination diagram (PCO) based on biochemical parameters, measured in Ruditapes philippinarum exposed to different MWCNT materials (Nf-MWCNTs and fMWCNTs) both at different concentrations $(0.00 ; 0.01 ; 0.10$ and $1.00 \mathrm{mg} / \mathrm{L})$. Pearson correlation vectors are superimposed as supplementary variables, namely biochemical data $(r>0.75)$ : PROT; GLY; LIP; ETS; SOD; GPx; GSTs; LPO; GSH/GSSG; ATChI-ChE. contaminated organisms and organisms exposed to the lowest concentration of unfunctionalized NMs $(0.01 \mathrm{mg} / \mathrm{L})$ were associated to ATChIChE, PROT, GLY and GSH/GSSG as these markers presented the highest values at these conditions. Individuals exposed to f-MWCNTs $(0.01$, 0.10 and $1.00 \mathrm{mg} / \mathrm{L}$ ) were closely related to SOD, GPx and LPO, where the highest values for these biomarkers were recorded. Organisms exposed to Nf-MWCNTS $(0.10$ and $1.00 \mathrm{mg} / \mathrm{L}$ ) were close related to ETS values, where higher ETS values were observed.

\section{Discussion}

CNTs functionalization technology is currently being used for creation of more soluble forms of carbon NMs for various medical and industrial products such as multifunctional composites, chemical and biological sensors, molecular electronics, fuel cells, super capacitors, lithium batteries, solar cells, and drug and gene delivery systems (Klaper et al., 2010). As compared to pristine and organic soluble carbon NMs, water-soluble CNTs have the highest probability of entering the human body and the aquatic environment (Klaper et al., 2010). There are two basic strategies to increase dispersibility of CNTs in water. The first one is the chemical functionalization of CNTs by introducing polar groups such as carboxyl groups and the other one is the physical functionalization of CNTs by adsorption of surfactants and polymers to decrease the van der Waals interaction (Shahnawaz et al., 2017). Carboxylation of SWCNTs, as well as MWCNTs, by introduction of polar groups such as carboxyl groups $(-\mathrm{COOH})$, showed to have more amorphous carbon fragments as a result of increased oxidation of carbon, and these amorphous fragments can induce higher levels of toxicity to biological systems compared to non-functionalized CNTs (Arndt et al., 2013). Our results are in agreement with the this finding, clearly showing that both Nf-MWCNTs and f-MWCNTs were able to generate oxidative stress in the exposed clams and were also responsible for changes in organisms' metabolism (expressed in alteration of energy reserves) and neurotoxicity induction in $R$. philippinarum, however greater impacts were caused by f-MWCNTs, namely in terms of metabolic capacity (GLY, LIP and ETS), and oxidative stress responses (LPO, GSH/GSSG, SOD and GPX) compared to Nf-MWCNTs.

Energy metabolism plays a fundamental role in organisms' survival and function, as well as in stress adaptation and tolerance (Sokolova et al., 2012). It was already demonstrated that once the organisms are exposed to pollutants they can increase energy expenditure (considered a mechanism of cellular protection) (Bielen et al., 2016). Recently, different authors demonstrated expenditure of energy reserves (expressed as a decrease of glycogen (GLY) and protein (PROT) content) in invertebrates exposed to carbon NMs (De Marchi et al., 2017b; De Marchi et al., 2017a; De Marchi et al., 2017c; De Marchi et al., 2017d). In agreement with such findings, the present study demonstrated that $R$. philippinarum decreased the GLY and PROT content when exposed to both f-MWCNTs and Nf-MWCNTs, which may indicate that clams were using GLY and PROT to fuel their mechanisms of defense against CNTs toxicity. Similarly, De Marchi et al. (2017b) studied the response of R. philippinarum exposed to two concentrations of MWCNT (0.10 and $1.00 \mathrm{mg} / \mathrm{L})$ under $\mathrm{pH}$ variations (control-7.9 and 7.6) for 28 days, and observed a decrease of PROT and GLY content at both salinity conditions.

Lipid (LIP) content is considered another important reserve of stored energy and has been also examined as an indicator of sub-lethal toxicity in invertebrates (Herbes and Allen, 1983). The relationship of LIP, as energy storage, and environmental stressors has been demonstrated by analyzing LIP components in marine invertebrates (Gardner et al., 1985; Abele and Puntarulo, 2004; Dickinson et al., 2012; Oliveira et al., 2017; Faggio et al., 2016; Messina et al., 2014). In the present study clams exposed to Nf-MWCNT preserved their LIP content while using GLY and PROT as primary energy source to fuel defense mechanisms against CNTs. However, when exposed to f-MWCNTs clams showed not only a decrease in GLY and PROT concentrations but also in LIP content. These results may probably indicate that f-MWCNTs may induce greater 
impacts than Nf-MWCNTs and therefore, more energy expenditure was necessary to fight against the impacts induced.

The balance between energy reserves (PROT, GLY and LIP) and mitochondrial electron transport system (ETS) activity is important to access if lower energetic availability can lead to impairment in organisms' reproduction and development (Smolders et al., 2004). The ETS activity can be used as a measure of metabolic capacity in different organisms (namely in invertebrates) in response to environmental disturbances (Cammen et al., 1990; Bielen et al., 2016; Freitas et al., 2016; Schmidlin et al., 2015; Simčič et al., 2014; Aliko et al., 2015),due to the ability to release the energy stored within the reduced hydrogen carriers in order to synthesize ATP (Liu et al., 2002). The results obtained in the present study clearly demonstrated that after 28 days exposure to both NfMWCNTs and f-MWCNTs, the clams presented increased metabolism (ETS) with the increase of exposure concentrations, which can be associated to energy expenditure observed at higher exposure concentrations. De Marchi et al. (2017b) also observed a slight increase of the ETS activity in $R$. philippinarum exposed to MWCNT concentrations under both $\mathrm{pH}$ conditions for 28 days.

The ETS activity has also been recognized as one of the major cellular generators of reactive oxygen species (ROS), which include superoxide $\left(\mathrm{O}_{2}^{-}\right)$, hydrogen peroxide $\left(\mathrm{H}_{2} \mathrm{O}_{2}\right)$ and the hydroxyl free radical $(-\mathrm{OH})$ (Liu et al., 2002). Mitochondrial ROS generation is a physiologically significant process in vivo, and that mitochondrial Superoxide-dismutase (SOD) is essential for maintaining the normal function of mitochondria-rich organs (Gomes et al., 2012). Biochemically, SOD is the enzyme responsible for the removal of the superoxide anion $\left(\mathrm{O}_{2}^{-}\right)$with formation of hydrogen peroxide $\left(\mathrm{H}_{2} \mathrm{O}_{2}\right)$ that can be used by Catalase (CAT) or Glutathione peroxidases (GPX) enzymes (which uses GSH as electron donor to catalyze the reduction of $\mathrm{H}_{2} \mathrm{O}_{2}$ to $\mathrm{H}_{2} \mathrm{O}$ ) (Regoli and Giuliani, 2014). Under stressful conditions, namely exposure to different NMs, ROS are overproduced. However invertebrate species are known to increase the activity of SOD in response to the generated oxidative stress (De Marchi et al., 2017b; De Marchi et al., 2017c; De Marchi et al., 2017d; Buffet et al., 2014a; Gomes et al., 2011; Buffet et al., 2011; Zhu et al., 2011; Mccarthy et al., 2013; Gomes et al., 2014; Gomes et al., 2012). In the present study clams exposed to Nf-MWCNTs and f-MWCNTs increased the activity of SOD, indicating the activation of this antioxidant mechanisms both when clams were exposed to Nf and f-MWCNTs, an enzymatic response to eliminate ROS and to prevent cellular damage (e.g. lipid peroxidation).

As mentioned above, despite being an antioxidant, SOD represents a source of $\mathrm{H}_{2} \mathrm{O}_{2}$, thus being necessary that its activity is coordinated with $\mathrm{H}_{2} \mathrm{O}_{2}$ reducing enzymes such as CAT or GPx (Regoli and Giuliani, 2014). Although GPx activity is proportionally lower in invertebrate than in vertebrate species compared to the other key antioxidant enzymes (CAT and SOD) (Gamble et al., 1995), the activation of this enzyme in invertebrate species when exposed to NMs has been demonstrated (De Marchi et al., 2017b; Volland et al., 2015; Gomes et al., 2014; Gomes et al., 2012). Considering clams exposed to Nf-MWCNTs in the present study, the antioxidant activity of GPx increased at $0.10 \mathrm{mg} / \mathrm{L}$, but decreased at the highest Nf-MWCNTs. This discrepancy may result from $\mathrm{H}_{2} \mathrm{O}_{2}$ produced by SOD that could be eliminated by GPx up to a certain level of stress, but at $1.00 \mathrm{mg} / \mathrm{L}$ (the highest exposure concentration) the enzyme activity could be inhibited due to a shift in the balance between oxidants and antioxidants in favor of oxidants, resulting in the increase of pollutantsinduced oxidative effect (Chatziargyriou and Dailianis, 2010). On the other hand, the activity of GPx was not inhibited in clams exposed to the two highest concentration of f-MWCNTs $(0.10$ and $1.00 \mathrm{mg} / \mathrm{L})$. Thus, our findings may indicate that the hydrogen peroxide produced by SOD is possibly being converted not by GPx but by other antioxidant systems which contribute in the defense against oxidative stress, e.g. CAT.

In the presence of NMs, invertebrates may also increase the activity of Glutathione-S-transferases (GSTs), a group of enzymes used as a biomarker to evaluate the detoxification capacity of organisms (Volker et al., 2014; Garaud et al., 2014; Cid et al., 2015; Minetto et al., 2014; Minetto et al., 2016; Ciacci et al., 2012). In the present study, the GSTs activity in clams exposed to Nf-MWCNTs slightly increased up to exposure concentrations of $0.10 \mathrm{mg} / \mathrm{L}$, indicating that these enzymes could be involved in detoxification of Nf-MWCNTs in R. philipinarum. In agreement with the present results, Cid et al. (2015), exposed Corbicula fluminea clams to $0.01,0.1,1$, and $10 \mathrm{mg} / \mathrm{L}$ of carbon nanodiamonds (NDs) throughout 14 days, and showed an increase of GSTs activity with increasing NDs concentration. However the behavior of the antioxidant enzymes is dependent on the type and concentration of the NMs (Canesi and Corsi, 2015). Indeed, in our study clams exposed to f-MWCNTs showed a decrease of GSTs activity with the increasing exposure concentration, indicating that these group of enzymes were not involved in the biotransformation of f-MWCNTs into less toxic excreted substance. In agreement with the present results, Anisimova et al. (2015) observed a decrease of GSTs activity in Crenomytilus grayanus mussels exposed to $12-14 \mathrm{~nm}$ diameter of MWCNTs (100 mg/L) after $48 \mathrm{~h}$.

Under stressful conditions, the excess of ROS produced by the organisms, may not be eliminated by defense mechanisms such as antioxidant enzymes leading to lipid peroxidation (LPO) (Regoli and Giuliani, 2014). Biochemically, ROS readily interact with polyunsaturated fatty acids of the fatty acid membrane, initiating a self-propagating chain reaction. The destruction of membrane lipids and the end-products of such LPO reactions are especially dangerous for the viability of cells, even tissues (Ayala et al., 2014). It has been proven that a major mechanism of toxicity for NMs is oxidative stress, associated with increases in reactive radicals that may affect the balance between antioxidants and oxidative damage, causing significant sub-lethal toxicity to organisms. Therefore, LPO has been used in invertebrates as an indicator of oxidative damage (De Marchi et al., 2017a; De Marchi et al., 2017b; Volland et al., 2015; De Marchi et al., 2017c; De Marchi et al., 2017d; Zhu et al., 2011; Mccarthy et al., 2013; Gomes et al., 2014; Cid et al., 2015; Anisimova et al., 2015; Ayala et al., 2014; Buffet et al., 2014b; Tedesco et al., 2010). In the present study, clams exposed to Nf-MWCNTs showed a gradual increase of LPO levels with the increase of exposure concentration, while clams submitted to f-MWCNTs presented a steeper increase of LPO levels at the lowest exposure concentration after which LPO only slightly increased, which may be associated with increased SOD activity at the two highest exposure concentrations. Anisimova et al. (2015) exposed C. grayanus to $12-14 \mathrm{~nm}$ diameter MWCNTs (100 mg/L) for $48 \mathrm{~h}$, and showed that CNTs were responsible for the increase of LPO levels. Using the same CNTs, De Marchi et al. (2017b) also showed increased LPO levels in organisms exposed to 0.10 and $1.00 \mathrm{mg} / \mathrm{L}$ MWCNTs under different pH levels (Correia et al., 2016; Wang et al., 2011) for 28 days.

Oxidative stress has often been associated to the reduced (GSH) and oxidized (GSSG) Glutathione ratio within the cell (Regoli and Giuliani, 2014). This ratio represents the major homeostatic regulator of redox equilibrium inside the cell and can be useful as a biomarker to detect protective or injurious cellular reactions by measuring the rate and level of ratio alterations (Mocan et al., 2010). NMs also showed to affect the processes involved in the maintenance of tissue redox balance in invertebrates, expressed as the decrease of GSH/GSSG (De Marchi et al., 2017b; De Marchi et al., 2017c; De Marchi et al., 2017d; Tedesco et al., 2010) and increase of GSH or GSSG content (Zhu et al., 2011; Anisimova et al., 2015; Falfushynska et al., 2015). In the present study GSH/GSSG values in organisms exposed to both MWCNT materials decreased with the increase of exposure concentrations (especially at 0.10 and $1.0 \mathrm{mg} / \mathrm{L}$ ), indicating that the stress induced by carbon NMs led to a decrease of GSH that was oxidized to GSSG. Using nonfunctionalized MWCNTs, Anisimova et al. (2015) observed GSH increased in hemolymph of $C$. grayanus on the second day of exposure in respect to control.

Recently the inhibition of cholinesterase in invertebrates has been used as a sensitive biomarker of exposure to various NMs (De Marchi et al., 2017b; Marisa et al., 2016; De Marchi et al., 2017c; Buffet et al., 2014a; Gomes et al., 2011; Luis et al., 2016; Buffet et al., 2014c). The 
Cholinesterases class includes specific cholinesterase (acetylcholinesterase $(\mathrm{AChE})$ ) and non-specific cholinesterase (or pseudo cholinesterase). AChE hydrolyses the neurotransmitter acetylcholine, producing choline and an acetate group (Lionetto et al., 2011). Among the various types of biomarkers studied, the inhibition of AChE activity receives special attention in ecotoxicological studies. Inhibition of AChE activity by NMs has been shown, and is primarily caused by adsorption or directly interaction with AChE (Lionetto et al., 2011). Our results revealed that both MWCNT materials impaired the hydrolytic activity of ChEs which resulted in a significant inhibition of AChE activity in $R$. philippinarum exposed to Nf-MWCNTs and f-MWCNTs compared to control. The decrease of the activity at all MWCNT exposure concentrations for both materials ( $\mathrm{Ng}$ and $\mathrm{f}$ ) may have been caused due to high affinity of MWCNT and SWCNT for AChE, and their ability to cause 76-88\% AChE activity reductions (Wang et al., 2009).

\section{Conclusion}

In the present study, it was clearly demonstrated that nanomaterial toxicity can be attributed to core structure and surface functionalization, which have been shown to alter the level of toxicity to biological systems. Considering the increase of the use of NMs in different fields and industrial applications and consequent release into aquatic ecosystems, the present study provides valuable information regarding the potential risk of MWCNTs in the aquatic environment and living organisms, namely economically relevant resources like $R$. philippinarum. However, there is still a lack of information regarding CNTs fate and toxicology in the aquatic environment. The study of the toxicity of these CNTs may lack of ecological relevance since in the environment different conditions may act in combination changing the behavior and toxicity of NMs. Consequently, future studies must include more realistic exposure scenarios to drive accurate safety levels toward biodiversity conservation.

\section{Acknowledgments}

Lucia De Marchi benefited from PhD grant (SFRH/BD/101273/2014), and Rosa Freitas benefited from post-doc grants (SFRH/BPD/92258/ 2013) given by the National Funds through the Portuguese Science Foundation (FCT), supported by FSE and Programa Operacional Capital Humano (POCH) e da União Europeia. This work was supported by the Integrated Programme of SR\&TD “Smart Valorization of Endogenous Marine Biological Resources Under a Changing Climate" (reference Centro01-0145-FEDER-000018), co-funded by Centro 2020 program, Portugal 2020, European Union, through the European Regional Development Fund. Thanks are also due, for the financial support to CESAM (UID/ $\mathrm{AMB} / 50017$ ), to FCT/MEC through national funds, and the co-funding by the FEDER, within the PT2020 Partnership Agreement and Compete 2020.

\section{References}

Abele, D., Puntarulo, S., 2004. Formation of reactive species and induction of antioxidant defence systems in polar and temperate marine invertebrates and fish. Comp. Biochem. Physiol. Part - A Mol. Integr. Physiol. 138 (4), 405-415.

Aliko, V., Hajdaraj, G., Caci, A., Faggio, C., 2015. Copper induced lysosomal membrane destabilisation in haemolymph cells of mediterranean green crab (Carcinus aestuarii, Nardo, 1847) from the Narta lagoon (Albania). Braz. Arch. Biol. Technol. 58 (5), 750-756.

Anisimova, A.A., Chaika, V.V., Kuznetsov, V.L., Golokhvast, K.S., 2015. Study of the influence of multiwalled carbon nanotubes $(12-14 \mathrm{~nm})$ on the main target tissues of the bivalve Modiolus modiolus. Nanotechnol. Russ. 10, 278-287.

Antunes, S.C., Freitas, R., Figueira, E., Gonçalves, F., Nunes, B., 2013. Biochemical effects of acetaminophen in aquatic species: edible clams Venerupis decussata and Venerupis philippinarum. Environ. Sci. Pollut. Res. 20 (9), 6658-6666.

Arndt, D.A., Moua, M., Chen, J., Klaper, R., 2013. Core structure and surface functionalization of carbon nanomaterials alter impacts to daphnid mortality, reproduction, and growth: acute assays do not predict chronic exposure impacts. Environ. Sci. Technol. 47 (16), 9444-9452.
Ayala, A., Muñoz, M.F., Argüelles, S., 2014. Lipid peroxidation: production, metabolism, and signaling mechanisms of malondialdehyde and 4-hydroxy-2-nonenal. Oxidative Med. Cell. Longev. 2014.

Baughman, R.H., Zakhidov, A.A., de Heer, W.A., 2002. Carbon nanotubes - the route toward J applications. Science 297 (5582), 787-792.

Beauchamp, C., Fridovich, I., 1971. Superoxide dismutase: improved assays and an assay applicable to acrylamide gels. Anal. Biochem. 44 (1), 276-287.

Bebianno, M.J., Géret, F., Hoarau, P., Serafim, M.A., Coelho, M.R., Gnassia-barelli, M., et al., 2004. Biomarkers in Ruditapes decussatus: a potential bioindicator species. Biomarkers 9 (4-5), 305-330.

Bielen, A., Bošnjak, I., Sepčić, K., Jaklič, M., Cvitanić, M., Lušić, J., et al., 2016. Differences in tolerance to anthropogenic stress between invasive and native bivalves. Sci. Total Environ. 543, 449-459.

Buffet, P.-E., Tankoua, O.F., Pan, J.-F., Berhanu, D., Herrenknecht, C., Poirier, L., et al., 2011. Behavioural and biochemical responses of two marine invertebrates Scrobicularia plana and Hediste diversicolor to copper oxide nanoparticles. Chemosphere 84 (1), $166-174$.

Buffet, P.E., Zalouk-Vergnoux, A., Châtel, A., Berthet, B., Métais, I., Perrein-Ettajani, H., et al., 2014a. A marine mesocosm study on the environmental fate of silver nanoparticles and toxicity effects on two endobenthic species: the ragworm Hediste diversicolor and the bivalve mollusc Scrobicularia plana. Sci. Total Environ. 470-471, 1151-1159.

Buffet, P.E., Poirier, L., Zalouk-Vergnoux, A., Lopes, C., Amiard, J.C., Gaudin, P., et al., 2014b. Biochemical and behavioural responses of the marine polychaete Hediste diversicolor to cadmium sulfide quantum dots (CdS QDs): waterborne and dietary exposure. Chemosphere 100, 63-70.

Buffet, P.-E., Zalouk-Vergnoux, A., Châtel, A., Berthet, B., Métais, I., Perrein-Ettajani, H., et al., 2014c. A marine mesocosm study on the environmental fate of silver nanoparticles and toxicity effects on two endobenthic species: the ragworm Hediste diversicolor and the bivalve mollusc Scrobicularia plana. Sci. Total Environ. 470-471, 1151-1159.

Burgos-Aceves, M.A., Faggio, C., 2017. An approach to the study of the immunity functions of bivalve haemocytes: physiology and molecular aspects. Fish Shellfish Immunol. 67, 513-517.

Cammen, L., Corwin, S., Christensen, J., 1990. Electron transport system (ETS) activity as a measure of benthic macrofaunal metabolism. Mar. Ecol. Prog. Ser. 65 (1), 171-182.

Canesi, L., Corsi, I., 2015. Effects of nanomaterials on marine invertebrates. Sci. Total Environ. 565, 933-940.

Cattaneo, A.G., Gornati, R., Bernardini, G., 2009. Ecotoxicology of nanomaterials: the role of invertebrate testing. Invertebr. Surviv. J. 6 (1), 78-97.

Chatziargyriou, V., Dailianis, S., 2010. The role of selenium-dependent glutathione peroxidase (Se-GPx) against oxidative and genotoxic effects of mercury in haemocytes of mussel Mytilus galloprovincialis (Lmk.). Toxicol. in Vitro 24 (5), 1363-1372.

Ciacci, C., Canonico, B., Bilaniĉovă, D., Fabbri, R., Cortese, K., Gallo, G., et al., 2012 Immunomodulation by different types of $\mathrm{N}$-oxides in the hemocytes of the marine bivalve Mytilus galloprovincialis. PLoS One 7 (5), 1-11.

Cid, A., Picado, A., Correia, J.B., Chaves, R., Silva, H., Caldeira, J., et al., 2015. Oxidative stress and histological changes following exposure to diamond nanoparticles in the freshwater Asian clam Corbicula fluminea (Müller, 1774). J. Hazard. Mater. 284, 27-34.

Coelho, J.P., Duarte, A.C., Pardal, M.A., Pereira, M.E., 2014. Scrobicularia plana (Mollusca, Bivalvia) as a biomonitor for mercury contamination in Portuguese estuaries. Ecol. Indic. 46, 447-453.

Correia, B., Freitas, R., Figueira, E., Soares, A.M.V.M., Nunes, B., 2016. Oxidative effects of the pharmaceutical drug paracetamol on the edible clam Ruditapes philippinarum under different salinities. Comp Biochem Physiol Part - C Toxicol Pharmacol. 179, 116-124.

De Coen, W., Janssen, C.R., 1997. The use of biomarkers in Daphnia magna toxicity testing. IV. Cellular energy allocation: a new methodology to assess the energy budget of toxicant-stressed Daphnia populations. J. Aquat. Ecosyst. Stress. Recover. 6, 43-55.

De Marchi, L., Neto, V., Pretti, C., Figueira, E., Chiellini, F., Soares, A.M.V.M., et al., 2017a. The impacts of emergent pollutants on Ruditapes philippinarum: biochemical responses to carbon nanoparticles exposure. Aquat. Toxicol. 187, 38-47.

De Marchi, L., Neto, V., Figueira, E., Pretti, C., Chiellini, F., Morelli, A., Soares, A.M.V.M., et al., 2017b. The impacts of seawater acidification on Ruditapes philippinarum sensitivity to carbon nanoparticles. Environ Sci Nano. 5-12.

De Marchi, L., Neto, V., Pretti, C., Figueira, E., Chiellini, F., 2017c. Physiological and biochemical responses of two keystone polychaete species: Diopatra neapolitana and Hediste diversicolor to multi-walled carbon nanotubes. Environ. Res. 154, 126-138.

De Marchi, L., Neto, V., Pretti, C., Figueira, E., Brambilla, L., Rodriguez-Douton, M.J., et al., 2017d. Physiological and biochemical impacts of graphene oxide in polychaetes: the case of Diopatra neapolitana. Comp. Biochem. Physiol. Part - C Toxicol. Pharmacol. 193, 50-60.

Dickinson, G.H., Ivanina, A.V., Matoo, O.B., Pörtner, H.O., Lannig, G., Bock, C., et al., 2012 Interactive effects of salinity and elevated $\mathrm{CO}_{2}$ levels on juvenile eastern oysters, Crassostrea virginica. J. Exp. Biol. 215 (1), 29-43.

Donaldson, K., Li, X.Y., MacNee, W., 1998. Ultrafine (nanometre) particle mediated lung injury. J. Aerosol Sci. 29 (5-6), 553-560.

Dubois, M., Gilles, K.A., Hamilton, J.K., Rebers, P.A., Smith, F., 1956. Colorimetric method for determination of sugars and related substances. Anal. Chem. 28 (3), 350-356.

Ellman, G.L., Courtney, K.D., Andres, V., Featherstone, R.M., 1961. A new and rapid colorimetric determination of acetylcholinesterase activity. Biochem. Pharmacol. 7 (2), 88-95.

Faggio, C., Pagano, M., Alampi, R., Vazzana, I., Felice, M.R., 2016. Cytotoxicity haemolymphatic parameters, and oxidative stress following exposure to sub-lethal concentrations of quaternium-15 in Mytilus galloprovincialis. Aquat. Toxicol. 180, 258-265.

Falfushynska, H., Gnatyshyna, L., Yurchak, I., Sokolova, I., Stoliar, O., 2015. The effects of zinc nanooxide on cellular stress responses of the freshwater mussels Unio tumidus are modulated by elevated temperature and organic pollutants. Aquat. Toxicol. 162, 82-93. 
Freitas, R., Almeida, Â., Pires, A., Velez, C., Calisto, V., Schneider, R.J., et al., 2015. The effects of carbamazepine on macroinvertebrate species: comparing bivalves and polychaetes biochemical responses. Water Res. 85, 137-147.

Freitas, R., Pires, A., Moreira, A., Wrona, F.J., Figueira, E., Soares, A.M.V.M., 2016. Biochemical alterations induced in Hediste diversicolor under seawater acidification conditions. Mar. Environ. Res. 117, 75-84.

Gamble, S.C., Goldfarb, P.S., Porte, C., Livingstone, D.R., 1995. Glutathione peroxidase and other antioxidant enzyme function in marine invertebrates (Mytifus edulis, Pecten maximus, Carcinus maenas and Asterias rubens). Mar. Environ. Res. 39, 191-195.

Garaud, M., Trapp, J., Devin, S., Felten, V., Giamberini, L., 2014. Multibiomarker assessment of cerium dioxide nanoparticle $\left(\mathrm{nCeO}_{2}\right)$ sublethal effects on two freshwater invertebrates, Dreissena polymorpha and Gammarus roeseli. Aquat. Toxicol. 158, 63-74.

Gardner, W.S., Frez, W.A., Cichocki, E.A., Parrish, C.C., 1985. Micromethod for lipids in aquatic invertebrates. Limnol. Oceanogr. 30 (5), 1099-1105.

Gomes, T., Pinheiro, J.P., Cancio, I., Pereira, C.G., Cardoso, C., Bebianno, M.J., 2011. Effects of copper nanoparticles exposure in the mussel Mytilus galloprovincialis. Environ. Sci. Technol. 45 (21), 9356-9362.

Gomes, T., Pereira, C.G., Cardoso, C., Pinheiro, J.P., Cancio, I., Bebianno, M.J., 2012. Accumulation and toxicity of copper oxide nanoparticles in the digestive gland of Mytilus galloprovincialis. Aquat. Toxicol. 118-119, 72-79.

Gomes, T., Pereira, C.G., Cardoso, C., Bebianno, M.J., 2013. Differential protein expression in mussels Mytilus galloprovincialis exposed to nano and ionic Ag. Aquat. Toxicol. 136137, 79-90.

Gomes, T., Pereira, C.G., Cardoso, C., Sousa, V., Teixeira, M.R., Pinheiro, J.P., et al., 2014. Effects of Silver Nanoparticles Exposure in the Mussel Mytilus galloprovincialis. pp. 1-7.

Habig, W.H., Pabst, M.J., Jakoby, W.B., 1976. Glutathione S-transferase AA from rat liver. Arch. Biochem. Biophys. 175 (2), 710-716.

Herbes, S.E., Allen, C.P., 1983. Lipid quantification of freshwater invertebrates: method modification for microquantitation. Can. J. Fish. Aquat. Sci. 40 (8), 1315-1317.

Hwang, Y., Lee, J.K., Lee, C.H., Jung, Y.M., Cheong, S.I., Lee, C.G., et al., 2007. Stability and thermal conductivity characteristics of nanofluids. Thermochim. Acta 455 (1-2), 70-74.

Jackson, P., Jacobsen, N.R., Baun, A., Birkedal, R., Kühnel, D., Jensen, K.A., et al., 2013. Bioaccumulation and ecotoxicity of carbon nanotubes. Chem. Cent. J. 7 (1), 154-165.

Kataoka, C., Nakahara, K., Shimizu, K., Kowase, S., Nagasaka, S., Ifuku, S., et al., 2016. Salinitydependent toxicity of water-dispersible, single-walled carbon nanotubes to Japanese medaka embryos. J. Appl. Toxicol. 37 (4), 408-416.

Khosravi-katuli, K., Prato, E., Lofrano, G., Guida, M., 2017. Effects of nanoparticles in species of aquaculture interest. Environ. Sci. Pollut. Res. 24 (21), 17326-17346.

King, F.D., Packard, T.T., 1975. Respiration and the activity of the respiratory electron transport system in marine zooplankton. Limnol. Oceanogr. 20, 849-854.

Klaper, R., Arndt, D., Setyowati, K., Chen, J., Goetz, F., 2010. Functionalization impacts the effects of carbon nanotubes on the immune system of rainbow trout, Oncorhynchus mykiss. Aquat. Toxicol. 100 (2), 211-217.

Lionetto, M.G., Caricato, R., Calisi, A., Schettino, T., 2011. Acetylcholinesterase inhibition as a relevant biomarker in environmental biomonitoring: new insights and perspectives. Ecotoxicology Around the Globe 87-115.

Liu, Y., Fiskum, G., Schubert, D., 2002. Generation of reactive oxygen species by the mitochondrial electron transport chain. J. Neurochem. 80 (5), 780-787.

Luis, L.G., Barreto, Â., Trindade, T., Soares, A.M.V.M., Oliveira, M., 2016. Effects of emerging contaminants on neurotransmission and biotransformation in marine organisms an in vitro approach. Mar. Pollut. Bull. 106 (1-2), 236-244.

Marisa, I., Matozzo, V., Munari, M., Binelli, A., Parolini, M., Martucci, A., et al., 2016. In vivo exposure of the marine clam Ruditapes philippinarum to zinc oxide nanoparticles: responses in gills, digestive gland and haemolymph. Environ. Sci. Pollut. Res. 23 (15), 15275-15293.

Matozzo, V., Pagano, M., Spinelli, A., Caicci, F., Faggio, C., 2016a. Pinna nobilis: a big bivalve with big haemocytes? Fish Shellfish Immunol. 55, 529-534.

Matozzo, V., Battistara, M., Marisa, I., Bertin, V., Orsetti, A., 2016b. Assessing the effects of amoxicillin on antioxidant enzyme activities, lipid peroxidation and protein carbony content in the clam Ruditapes philippinarum and the mussel Mytilus galloprovincialis. Bull. Environ. Contam. Toxicol. 97 (4), 521-527.

Matranga, V., Corsi, I., 2012. Toxic effects of engineered nanoparticles in the marine environment: model organisms and molecular approaches. Mar. Environ. Res. 76, 32-40.

Mccarthy, M.P., Carroll, D.L., Ringwood, A.H., 2013. Tissue specific responses of oysters, Crassostrea virginica, to silver nanoparticles. Aquat. Toxicol. 138-139, 123-128.

Mennillo, E., Casu, V., Tardelli, F., De Marchi, L., Freitas, R., Pretti, C., 2017. Suitability of cholinesterase of polychaete Diopatra neapolitana as biomarker of exposure to pesticides: In vitro characterization. Comp. Biochem. Physiol. Part - C Toxicol. Pharmacol. 191, 152-159.

Messina, C.M., Faggio, C., Laudicella, V.A., Sanfilippo, M., Trischitta, F., Santulli, A., 2014. Effect of sodium dodecyl sulfate (SDS) on stress response in the Mediterranean musse (Mytilus galloprovincialis): regulatory volume decrease (Rvd) and modulation of biochemical markers related to oxidative stress. Aquat. Toxicol. 157, 94-100.

Miller, M.A., Bankier, C., Al-shaeri, M.A.M., Hartl, M.G.J., 2015. Neutral red cytotoxicity assays for assessing in vivo carbon nanotube ecotoxicity in mussels - comparing microscope and microplate methods. MPB 101 (2), 903-907.

Minetto, D., Libralato, G., Volpi Ghirardini, A., 2014. Ecotoxicity of engineered $\mathrm{TiO}_{2}$ nanoparticles to saltwater organisms: an overview. Environ. Int. 66, 18-27.

Minetto, D., Ghirardini, A.V., Libralato, G., 2016. Saltwater ecotoxicology of Ag, Au, CuO, $\mathrm{TiO}_{2}$, $\mathrm{ZnO}$ and C60 engineered nanoparticles: an overview. Environ. Int. 92-93, 189-201.

Mocan, T., Clichici, S., Mocan, L., Simon, S., Ilie, I.R., Biriş, A.R., 2010. Implications of oxidative stress mechanisms in toxicity of nanoparticles (review). Acta Physiol. Hung. 97 (3), 247-255.

Moon, Y.K., Lee, J., Lee, J.K., Kim, T.K., Kim, S.H., 2009. Synthesis of length-controlled aerosol carbon nanotubes and their dispersion stability in aqueous solution. Langmuir 25 (3), $1739-1743$.
Moura, P., Garaulet, L.L., Vasconcelos, P., Chainho, P., Costa, J.L., Gaspar, M.B., 2017. Age and growth of a highly successful invasive species: the manila clam Ruditapes philippinarum (Adams \& Reeve, 1850) in the Tagus estuary (Portugal). Aquat. Invasions 12 (2), 133-146.

Ohkawa, H., Ohishi, N., Yagi, K., 1979. Assay for lipid peroxides in animal tissues by thiobarbituric acid reaction. Anal. Biochem. 95 (2), 351-358.

Oliveira, P., Almeida, Â., Calisto, V., Esteves, V.I., Schneider, R.J., Wrona, F.J., et al., 2017. Physiological and biochemical alterations induced in the mussel Mytilus galloprovincialis after short and long-term exposure to carbamazepine. Water Res. 117, 102-114.

Pagano, M., Capillo, G., Sanfilippo, M., Palato, S., Trischitta, F., Manganaro, A., et al., 2016. Evaluation of functionality and biological responses of Mytilus galloprovincialis after exposure to quaternium-15 (Methenamine 3-Chloroallylochloride). Molecules 21 (2), 1-12.

Pagano, M., Porcino, C., Briglia, M., Fiorino, E., Vazzana, M., Silvestro, S., et al., 2017. The influence of exposure of cadmium chloride and zinc chloride on Haemolymph and digestive gland cells from Mytilus galloprovincialis. Int. J. Environ. Res. 11 (2), 207-216.

Paglia, D.E., Valentine, W.N., 1967. Studies on the quantitative and qualitative characterization of erythrocyte glutathione peroxidase. J. Lab. Clin. Med. 70 (1), 158-169.

Petersen, E.J., Henry, T.B., 2012. Methodological considerations for testing the ecotoxicity of carbon nanotubes and fullerenes: review. Environ. Toxicol. Chem. 31 (1), 60-72.

Potočnik, J., 2011. Commission recommendation of 18 October 2011 on the definition of nanomaterial (2011/696/EU). Off. J. Eur. Union L275, 38-40.

Rahman, S., Kim, K.H., Saha, S.K., Swaraz, A.M., Paul, D.K., 2014. Review of remediation techniques for arsenic (As) contamination: a novel approach utilizing bio-organisms. J. Environ. Manag. 134, 175-185.

Regoli, F., Giuliani, M.E., 2014. Oxidative pathways of chemical toxicity and oxidative stress biomarkers in marine organisms. Mar. Environ. Res. 93, 106-117.

Robinson, H.W., Hogden, C.G., 1940. The biuret reaction in the determination of serum proteins. 1. A study of the conditions necessary for the production of a stable color which bears a quantitative relationship to the protein concentration. J. Biol. Chem. 135, 707-725.

Sanchez, V.C., Jachak, A., Hurt, R.H., Kane, A.B., 2012. Biological interactions of graphenefamily nanomaterials-an interdisciplinary review. Chem. Res. Toxicol. 15-34

Savorelli, F., Manfra, L., Croppo, M., Tornambè, A., Palazzi, D., Canepa, S., et al., 2017. Fitness evaluation of Ruditapes philippinarum exposed to Ni. Biol. Trace Elem. Res. 177 (2), 384-393.

Schmidlin, L., von Fumetti, S., Nagel, P., 2015. Temperature effects on the feeding and electron transport system (ETS) activity of Gammarus fossarum. Aquat. Ecol. 49 (1), 71-80.

Shahnawaz, S., Sohrabi, B., Najafi, M., 2017. The Investigation of Functionalization Role in Multi-walled Carbon Nanotubes Dispersion by Surfactants. In Proceedings of the 18th Int. Electron. Conf. Synth. Org. Chem., 1-30 November 2014; Sciforum Electronic Conference Series Vol. 18 f002.

Simčič, T., Pajk, F., Jaklič, M., Brancelj, A., Vrezec, A., 2014. The thermal tolerance of crayfish could be estimated from respiratory electron transport system activity. J. Therm. Biol. 41 (1), 21-30.

Smolders, R., Bervoets, L., Coen, W., De Blust, R., 2004. Cellular energy allocation in zebra mussels exposed along a pollution gradient: linking cellular effects to higher levels of biological organization. Environ. Pollut. 129 (1), 99-112.

Sokolova, I.M., Frederich, M., Bagwe, R., Lannig, G., Sukhotin, A.A., 2012. Energy homeostasis as an integrative tool for assessing limits of environmental stress tolerance in aquatic invertebrates. Mar. Environ. Res. 79, 1-15.

Sun, Y., Fu, K., Lin, Y.I., 2002. Functionalized carbon nanotubes: properties and applications. Acc. Chem. Res. 35 (12), 1096-1104.

Sun, T.Y., Bornhöft, N.A., Hungerbühler, K., Nowack, B., 2016. Dynamic probabilistic modeling of environmental emissions of engineered nanomaterials. Environ. Sci. Technol. 50 (9), 4701-4711

Tedesco, S., Doyle, H., Blasco, J., Redmond, G., Sheehan, D., 2010. Oxidative stress and toxicity of gold nanoparticles in Mytilus edulis. Aquat. Toxicol. 100 (2), 178-186.

Torre, A., Trischitta, F., Corsaro, C., Mallamace, D., Faggio, C., 2013a. Digestive cells from Mytilus galloprovincialis show a partial regulatory volume decrease following acute hypotonic stress through mechanisms involving inorganic ions. Cell Biochem. Funct. 31 (6), 489-495

Torre, A., Trischitta, F., Faggio, C., 2013b. Effect of $\mathrm{CdCl}_{2}$ on regulatory volume decrease (RVD) in Mytilus galloprovincialis digestive cells. Toxicol. in Vitro 27 (4), 1260-1266.

Velez, C., Figueira, E., Soares, A.M.V.M., Freitas, R., 2016. The impacts of as accumulation under different pH levels: comparing Ruditapes decussatus and Ruditapes philippinarum biochemical performance. Environ. Res. 151, 653-662.

Verdelhos, T., Neto, J.M., Marques, J.C., Pardal, M.A., 2005. The effect of eutrophication abatement on the bivalve Scrobicularia plana. Estuar. Coast. Shelf Sci. 63 (1-2), 261-268.

Volker, C., Kampken, I., Boedicker, C., Oehlmann, J., Oetken, M., 2014. Toxicity of Silver Nanoparticles and Ionic Silver: Comparison of Adverse Effects and Potential Toxicity Mechanisms in the Freshwater Clam Sphaerium corneum. 5390 pp. 1-9.

Volland, M., Hampel, M., Martos-Sitcha, J.A., Trombini, C., Martínez-Rodríguez, G., Blasco, J., 2015. Citrate gold nanoparticle exposure in the marine bivalve Ruditapes philippinarum: uptake, elimination and oxidative stress response. Environ. Sci. Pollut. Res. 22 (22), 17414-17424.

Vonk, J.A., Struijs, J., van de Meent, D., Peijnenburg, W., 2010. Nanomaterials in the Aquatic Environment: Toxicity, Exposure and Risk Assessment RIVM rapport 607794001.

Wang, Z., Zhao, J., Li, F., Gao, D., Xing, B., 2009. Chemosphere adsorption and inhibition of acetylcholinesterase by different nanoparticles. Chemosphere 77 (1), 67-73.

Wang, X., Xia, T., Ntim, S.A., Ji, Z.X., George, S., Meng, H., et al., 2010. Quantitative techniques for assessing and controlling the dispersion and biological effects of multiwalled carbon nanotubes in mammalian tissue culture cells. ACS Nano 4 (12), 7241-7252.

Wang, L., Pan, L., Liu, N., Liu, D., Xu, C., Miao, J., 2011. Biomarkers and bioaccumulation of clam Ruditapes philippinarum in response to combined cadmium and benzo $\alpha]$ pyrene exposure. Food Chem. Toxicol. 49 (12), 3407-3417. 
Xu, H., Cheng, X., Zhong, J., Meng, J., Yang, M., Jia, F., et al., 2011. Characterization of multiwalled carbon nanotubes dispersing in water and association with biological effects. J. Nanomater. 2011.

Yesudhason, P., Al-Busaidi, M., Al-Rahbi, W.A.K., Al-Waili, A.S., Al-Nakhaili, A.K., AlMazrooei, N.A., et al., 2013. Distribution patterns of toxic metals in the marine oyster Saccostrea cucullata from the Arabian Sea in Oman: spatial, temporal, and size variations. Spring 2 (1), 282.

Yi, Y.C., Jean, Z., 2011. Rapid quantitative analysis of lipids using a colorimetric method in a microplate format. Lipids 46 (1), 95-103.
Zhang, L., Liu, X., You, L., Zhou, D., Wang, O., Li, F., et al., 2011. Benzo(a)pyrene-induced metabolic responses in Manila clam Ruditapes philippinarum by proton nuclear magnetic resonance (1H NMR) based metabolomics. Environ. Toxicol. Pharmacol. 32 (2) 218-225.

Zhu, X., Zhou, J., Cai, Z., 2011. The toxicity and oxidative stress of $\mathrm{TiO}_{2}$ nanoparticles in marine abalone (Haliotis diversicolor supertexta). Mar. Pollut. Bull. 63 (5-12), 334-338. 